\title{
Adorno e os estertores da derradeira chance do pensamento
} Adorno and the death rattles of the last chance of thought

Marcelo Leandro dos Santos ${ }^{1}$

Resumo: Este artigo discute o sentido pretendido por Adorno com a expressão "derradeira chance do pensamento". Para tal, busca-se uma aproximação entre alguns elementos presentes nas seções 1 e 41 de Minima moralia, em especial: o intelectual independente e o filósofo-escritor como porta-vozes da crítica à falta de originalidade na produção filosófica.

Palavras-chave: crítica filosófica, sistema, originalidade, razão técnica.

Abstract: This paper argues the meaning intended by Adorno with the expression "last chance of thought”. For this, it seeks out, approach some elements present in the Minima moralia's sections 1 and 41, particularly: the independent intellectual and the philosopher-writer as spokesmen of the criticism to lack of originality in the philosophical production.

Keywords: philosophical criticism, system, originality, technical reason.

\section{Introdução}

Uma das apropriações mais comuns que se costuma fazer do pensamento de Adorno consiste em catalogá-lo como assistemático. Nisto há uma pequena armadilha, pois raramente fica suficientemente claro o que se entende pelo termo assistemático. E, por vezes, tal catalogação pode se dar tanto em contextos intelectuais que consideram a assistematicidade uma característica depreciativa, quanto por contextos completamente opostos, que a consideram uma grande virtude intelectual. E é ainda mais paradoxal quando muitos daqueles que admiram esta suposta assistematicidade ainda não tenham entendido muito bem o porquê dessa admiração. É claro que sem esta última disposição subjetiva não existiria uma condição determinante para os modelos econômicos dos últimos séculos: a moda.

${ }^{1}$ Universidade do Vale do Taquari (Univates), Lajeado, RS, <marcelolean.s@gmail.com>. 
Mas fiquemos, por enquanto, com aqueles que veem a assitematicidade adorniana com desconfiança. Para estes a atividade filosófica consiste, por si só, na busca pela sistematicidade. Nessa perspectiva, filosofia e sistema estariam tão entrelaçados que ousar pensar fora do sistema (ou apesar dele) não faria o menor sentido. É também nessa perspectiva que se pode entender a dificuldade de reconhecer Adorno como herdeiro legítimo de Hegel, uma vez que este último é largamente identificado com a ideia de sistema. Sistema, aliás, virou uma espécie de jargão sobre o pensamento hegeliano. Contudo, nem Hegel é apenas sistema e muito menos a filosofia, mesmo quando pensada como um todo. Na perspectiva adorniana sempre restará algo sobre o qual se possa filosofar, transcendendo qualquer pretensão de totalidade.

Sempre incomodado com todo pensamento pretensioso, cujo vocabulário comumente é habitado por jargões e clichês, Adorno investe na direção contrária. Em razão disso, seus textos assumem a tarefa de desprender o filosofar das teias da linguagem técnica. Para muitos, isto é traduzido como assistematicidade.

Já na época de Adorno o ambiente acadêmico demonstrava habilidade em produções intelectuais inférteis, encurraladas em seus próprios domínios burocráticos. Nesse sentido, torna-se menos difícil de subentender as motivações que fazem o status quo projetar desprezo sobre o pensamento adorniano, quando este é catalogado como assistemático. Mas esta eventual rejeição é para Adorno a prova real da potencialidade de seu pensamento. Pois o estigma de assistemático nada mais é que disposição crítica, a qual acaba por perturbar certo estado de coisas que se apresenta, de modo arrogante, como guardião do sistema.

As percepções de Adorno demonstram sua consistência e atualidade ao se observar o comportamento acadêmico na recepção de um pensador. O cenário mostra, repetidas vezes, que tal momento dissimula certa pompa ao tentar decodificar um método próprio nesse pensador-outro que está sendo recepcionado. Em tais horas, a pretensão científica busca abstrair aquilo que não existe, a saber, a essência do pensamento de um alguém. Esgotada a técnica metodológica, expõe-se o que se conseguiu apreender desse pensamento em um belo mosaico de jargões, com orgulho análogo ao do caçador que expõe seus cadáveres em sua sala de estar. Contudo, filosofia não é taxidermia. Não é possível abater um pensamento e ainda preservar-lhe suas características. Para entender sua existência, 
ele deve ser mantido em suas condições vitais, o que significa que os elos conceituais e as motivações concretas que interligam sua linguagem própria são preponderantes. Se observado esse critério torna-se possível testemunhar a pobreza ou a riqueza de qualquer abordagem intelectual. Mas para isso o observador deve estar realmente consciente a respeito de seu âmbito moral, intelectual e, sobretudo, de seus afetos; condição que, como bem se sabe desde Nietzsche, não pertence à tradição filosófica.

Ao considerar as características da esfera institucional e das interrelações - por vezes degradantes e ressentidas - em que se dá a oficialidade do pensamento, nota-se que o estilo adorniano impõe a exigência de disposições transdisciplinares como pressupostos óbvios para uma intensidade crítica que realmente ultrapasse veladas pretensões de culto. Essa tonalidade do pensamento se mostra como preocupação madura no Prefácio de Dialética do esclarecimento, quando juntamente com Horkheimer se propõem a abandonar uma antiga confiança que ambos tinham "no desenvolvimento de temáticas especializadas"². Já não basta dominar sociologia, psicologia, epistemologia etc. Mesmo se considerassem a possibilidade de o problema ser resumido a uma questão de aplicação de saberes, estes autores se deram conta de que não poderia haver um especialista nas verdadeiras urgências de um século em ruínas e que, ainda que ocorresse tal milagre, não surgiria da cátedra semelhante redenção. A tradição do conhecimento raramente está à altura da dimensão dos problemas que tem em mãos. É nesse sentido que Adorno vê na figura do especialista certa incompetência constitutiva diante do colapso, o qual não se consegue contextualizar de modo adequado nos moldes da tradição científica.

Assim, o presente artigo analisa características do pensamento adorniano que questionam a operacionalidade presente no meio intelectual e acadêmico. As nuances concretas dessa operacionalidade serão aqui mais diretamente observadas nas seções 1 e 41 de Minima moralia, nas quais Adorno utiliza figuras que orbitam o universo intelectual para expor uma realidade implícita às relações intelectuais, inclusive no contexto acadêmico. Assim, a intenção de Adorno é ilustrar o contraste entre as diferentes potencialidades que abordam os problemas

\footnotetext{
${ }^{2}$ HORKHEIMER, Max; ADORNO, Theodor. Dialética do esclarecimento. Tradução de Guido de Almeida. Rio de Janeiro: Jorge Zahar, 1985, p. 11.
} 
filosóficos de sua época. Obviamente, ele faz isso frustrando completamente qualquer expectativa sistêmica. Uma vez exposto tal jogo de relações, torna-se um pouco menos pesado respirar o rarefeito ar messiânico contido na expressão "derradeira chance do pensamento", também uma elaboração adorniana.

\section{$2 \mathrm{O}$ intelectual independente}

Intitulada "Para Marcel Proust", a primeira seção de Minima moralia apresenta uma incomum reflexão sobre um tema aparentemente desimportante. "Quem é filho de pais abastados e, não importa se por talento ou fraqueza, escolhe uma das profissões ditas intelectuais, como artista ou estudioso, enfrenta dificuldades especiais entre aqueles que levam o desagradável nome de colegas"3, escreve Adorno já na primeira frase desta seção. Adorno conduz o leitor a pensar em Proust, com o qual essa realidade se identifica diretamente, uma vez que seu pai e sua mãe eram muito ricos. Mas ele não está se referindo, de modo vulgar, ao privilégio de não precisar trabalhar, pois, afinal, Proust trabalhou - e muito. Basta lembrar que no período final de sua vida passava praticamente quase todo o tempo trancado em seu quarto escrevendo a obra que consagraria seu nome. Trata-se, portanto, de um homem que literalmente se esgotou de tanto trabalhar. A principal questão de Adorno, nesta seção, portanto, é outra: também a atividade humana do trabalho intelectual está sequestrada pela mesma ideologia que comanda a produção nas fábricas. "A ocupação com coisas espirituais tornou-se, entrementes, ela própria uma atividade 'prática', um negócio marcado pela rígida divisão do trabalho, com ramificações e numerus clausus" escreve Adorno, também um homem que vivera a condição de ser filho de pais abastados e que, se aproveitasse a posição de seu pai na sociedade, em vez de se envolver com questões intelectuais poderia tranquilamente ter escolhido qualquer outra atividade que o colocasse imediatamente no topo hierárquico da ideologia vigente de produção.

Evidentemente, não foi esse o destino que Adorno escolheu para si. E, embora dedicado a Proust, de algum modo esta seção tem um caráter

\footnotetext{
${ }^{3}$ ADORNO, Theodor. Minima moralia: reflexões a partir da vida danificada. Tradução Luiz Eduardo Bicca. São Paulo: Ática, 1993, p. 15 .

${ }^{4}$ Ibidem.
} 
confessional, que ajuda a marcar, de saída, o tom de lamento que prevalecerá em Minima moralia. Certamente é desolador ser atacado em seu meio profissional justamente por causa de escolhas livres e idôneas. "A suspensão da divisão do trabalho, a que se vê impelido e que sua situação econômica lhe consente realizar dentro de certos limites, é de especial má-fama"5, lamenta Adorno, revelando que a perspectiva institucional vê o intelectual independente como diletante ${ }^{6}$, cuja pele é tatuada por suspeitas maliciosas a respeito de suas atividades. Tais suspeitas, não raramente, o meio acadêmico dissemina para além de seus bastidores. Que legitimidade teria um burguês bem nascido para se queixar da vida? Como explicar essa excentricidade no meio intelectual marxista?

Sempre presente nos sistemas totalitários como estratégia política, a prática da difamação quando habita o meio intelectual tem o claro propósito de diluir a integridade daqueles que demonstram "aversão a sancionar as atividades recomendadas pela sociedade - e a competência dominante não tolera tais idiossincrasias" ", complementa Adorno. É muito comum ouvir - inclusive de pessoas muito bem intencionadas - que Adorno seria um pensador elitista, e, por causa disso, inapropriado para a abordagem teórica de certos problemas humanísticos da contemporaneidade. Observações dessa natureza apenas comprovam que a Filosofia em particular e as Ciências Humanas em geral se distanciaram de sua originalidade, pois departamentalizaram o espírito a tal ponto de não mais reconhecê-lo como fim de suas atividades. "A departamentalização do Espírito é um meio de eliminar este último onde ele não é exercido ex officio, por incumbência" ${ }^{8}$, destaca Adorno.

$\mathrm{Na}$ ânsia de se mostrar útil, as preocupações acadêmicas se tornam reféns das leis do mercado. Lutam tanto para justificar alguma praticidade de suas teorias que as próprias causas intelectuais só têm vida fora do gabinete, aguardando serem assumidas como missão pessoal justamente por aquele que não está nem aí para as pressões econômicas. No fim das contas, o intelectual independente foi desacreditado não por sua

\footnotetext{
${ }^{5}$ Ibidem.

${ }^{6}$ Cf. ADORNO, 1993, p. 15 .

${ }^{7}$ ADORNO, 1993, p. 15

${ }^{8}$ Ibidem.
} 
capacidade intelectual, evidentemente, mas por não precisar se render à lógica que impera no mundo intelectual e que todos se esforçam para negar: o dinheiro.

Em vez de lamentar que os pobres morrem de fome por causa do dinheiro que as elites acumularam, Adorno lamenta o fato de a expectativa intelectual oficial não ser capaz de perceber que ela mesma tem seu eco reduzido por sustentar interesse velado na mesma causa que aparenta criticar, a saber, acumular dinheiro. Nesse sentido, o termo colega é pejorativo para Adorno, pois são os colegas que perpetuam uma rede de relações onde os verdadeiros interesses que comungam são silenciados, embora sempre subjacentes às práticas que envolvem poder. Aliás, é no modo como ocupam seus papéis na sociedade produtiva que os colegas edificam o chamado mundo profissional, que será usado em um jogo dissimulado de oposições para legitimar a intolerância ao intelectual independente:

Quem é materialmente independente e a escolhe [ocupação com coisas espirituais] por repugnância à vergonha que é ganhar dinheiro, não se inclinará a reconhecer isso. Por isso é penalizado. Ele não é um professional: na hierarquia dos concorrentes, sua posição é a de um diletante, pouco importa quão competente seja, e, se pretende fazer carreira, tem de sobrepujar, em obstinação e estreiteza mental, o mais turrão do especialistas. ${ }^{9}$

Embora muitas vezes não se dê conta, o intelectual independente é agraciado com a possibilidade da autenticidade exclusivamente por sua condição lhe permitir prescindir de glorificar os esquemas conceituais chancelados pelo professional. O próprio adjetivo, mantido em inglês por Adorno, indica que na cultura norte-americana (e agora global) é considerado um traço de caráter apreciado. Porém, do ponto de vista filosófico, a partir do contexto colocado por Adorno, haveria muita dificuldade em justificar o profissionalismo como virtude. Assim como o intelectual independente, o profissional também é cúmplice da triste realidade de que este mundo, do modo como está disposto, é um erro. Contudo, caso se quisesse acusar o intelectual independente e o 
profissional de cinismo, Adorno só veria alguma chance de o primeiro ser absolvido. Assim reza o discurso edificado pelo mundo administrado:

\begin{abstract}
Zela-se assim pela ordem: uns têm que se conformar porque, de outro modo, não podem viver; outros, que poderiam viver de outro modo, são deixados de fora porque não querem se conformar. É como se a classe desertada pelos intelectuais independentes se vingasse na medida em que suas exigências se impõem forçosamente lá onde o desertor busca refúgio. $^{10}$
\end{abstract}

Quase pautado em uma profecia, Adorno encerra esta seção expondo o espírito totalizante da ordem vigente. A classe aparece mantendo relação com aquele que dela voluntariamente se aparta, mas oficialmente é ela quem o marginaliza. Adorno reflete sobre a verdade que contém todos esses desdobramentos, pois está ciente de que qualquer versão que busca oficialidade é sempre suscetível de ser fraudada em nome de uma dialética apoteótica.

\title{
30 filósofo-escritor
}

A seção 41 de Minima moralia traz em seu título - "Dentro e fora" - a continuidade do tema abordado na seção 1. Como visto, a ordem consegue marcar a todos com as insígnias "dentro" ou "fora". O fato de a ordem nazista ter feito o mesmo de modo mais explícito e cruel não é mera coincidência. O intelectual independente continua do lado de fora, mas na seção 41 seu análogo é o filósofo cujo escrito, obviamente, demonstra ser produto de certo distanciamento da lógica acadêmica. A diferença é que este último não goza das mesmas prerrogativas de segurança econômica que o primeiro. Ou seja, trata-se de um filósofo que precisa ganhar seu pão. "O filósofo que pretende ganhar a vida como escritor vê-se, por assim dizer, a todo instante obrigado a oferecer um produto refinado de escol, e a se afirmar pelo monopólio da originalidade contra o monopólio da instituição"11, escreve Adorno, apresentando o filósofo-escritor como aquele que tem a dura tarefa de oferecer o que há de melhor como produto final. E a sociedade - que tudo absorve como produto seu - espera as

\footnotetext{
${ }^{10}$ Ibidem.

${ }^{11}$ Ibidem, p. 57.
} 
pérolas do filósofo-escritor sob a aura do que os pedantes chamam de "iguaria intelectual" 12 .

Como a fome diária se mata com alimentos triviais, não é o filósofoescritor quem vai saciar a voracidade da oficialidade. Ele é responsável pelos momentos exóticos, pois, afinal, não se dispõe a glorificar a oficialidade. "Quem oferece algo único, que ninguém mais quer comprar, representa, mesmo contra sua vontade, a liberdade de troca" ${ }^{13}$, aponta Adorno.

Na sua condição de exceção, o escrito como iguaria justifica inclusive a existência-zumbi da filosofia nos quadros acadêmicos. "Por piedade, desmazelo e cálculo deixa-se a filosofia continuar o seu trabalho" ${ }^{14}$, afirma Adorno, como se até mesmo a fenda messiânica pudesse ser abrangida pelo projeto em curso que visa substituir a filosofia por "tautologia organizada" ${ }^{5}$. Diante da máquina de sucção produtiva, o filósofo-escritor, além de servir como bagaço da laranja - papel que a classe operária conhece desde sempre - ainda é transformado em caricatura da semiformação [Halbbildung] por seu estilo de vida levá-lo "a uma afinidade fatal com as ocupações artísticas”" ${ }^{16}$. De tanto especializarse em iguarias, sua maldição será o Kitsch espiritual como quinta-essência. Não por acaso, Adorno entende toda busca por especialização como potencialmente doentia. A figura do colega, que reaparece nesta seção, novamente é usada por Adorno como arquétipo do ser humano esvaziado de sua originalidade. Porque, ao contrário dele, o filósofo-escritor buscava oferecer alguma originalidade nas "coisas do espírito". O interessante é que, ainda assim, Adorno não é um apologeta do filósofo-escritor, pois está atento aos perigos oriundos da atividade deste último. Entre esses perigos, Adorno vê uma pista para a disposição intelectual que propiciou o fascismo:

A Munique de antes da Primeira Guerra Mundial era uma incubadora daquela espiritualidade cujo protesto contra o racionalismo acadêmico, passando pelos cultos do baile de mascaras, desembocou ainda mais

\footnotetext{
${ }^{12}$ Ibidem.

${ }^{13}$ Ibidem, p. 58.

${ }^{14}$ Ibidem, p. 57.

${ }^{15}$ Ibidem.

${ }^{16}$ Ibidem.
} 
rapidamente no fascismo do que o desalentado sistema do velho Rickert. É tão grande o poder da progressiva organização do pensamento que aqueles que desejam manter-se fora dela são impelidos para a vaidade ressentida, a verborragia da autopromoção e finalmente, no caso dos menos capazes, para a impostura intelectual. ${ }^{17}$

Obcecado pelo alto refino de seu produto final e sem identificação cotidiana com a estrutura institucional, a quem seu produto se destina, o filósofo-escritor precisa considerar que, apesar de tudo, deve pisar em terreno minimamente ético. Não há uma completa existência outsider, que de tanto submeter seu espírito ao exercício alquímico pudesse dar-se ao luxo de levitar sobre o solo onde se assenta a realidade. Quanta dessa suspensão não foi reordenada pelo fascismo como arquitetura de discursos ressentidos? Quantos intelectuais apresentados como excluídos não teriam visto no fascismo sua hora e sua vez? O diagnóstico é dado com exatidão por Adorno: "Aos tipos compulsivos lá, correspondem aqui os paranóicos" ${ }^{18}$.

\section{A derradeira chance do pensamento}

As problematizações até aqui apresentadas não se constituem em elogio às posturas do intelectual independente e do filósofo-escritor. Como já percebido, Adorno não é um pensador que busca edificar um lugar próprio para a Filosofia, tampouco confeccionar ídolos literários. Muito pelo contrário. Ele não se impõe tal trabalho, pois é conscientemente um condenado da ruína do tempo - no mais apropriado sentido benjaminiano que possa ser dado ao termo ruína. Nesse sentido, o que uma abordagem banal entende como característica assistemática tem a ver com o modo precário como essa abordagem foi feita. Dizer teoricamente que Adorno é, por princípio, anti-edificante e antiglorificante - e ainda assim sério e incisivo - é um reconhecimento que custaria muito caro à abordagem oficial. Para a via adorniana o destino crítico consiste em esforçar-se conceitualmente por uma linguagem que possa pronunciar o estreitamento ao qual a vida (em todas suas manifestações) fora submetida; empreitada melancólica, por excelência.

\footnotetext{
${ }^{17}$ Ibidem.

${ }^{18}$ Ibidem, p. 58 .
} 
Aquilo que "vida" significava outrora para os filósofos passou a fazer parte da esfera privada e, mais tarde ainda, da esfera do mero consumo, que o processo de produção material arrasta consigo como um apêndice sem autonomia e sem substância própria. ${ }^{19}$

Nesta preocupação adorniana com a vida, as figuras trazidas à luz - intelectual independente e filósofo-escritor - de algum modo humano (demasiado humano) expõem, em suas existências que não se contentam com a disposição ordinária, a face ocultada daquilo que se pode entender provisoriamente como sistema. A questão adorniana não é precisamente ser assistemático para situar-se como um oposto binário. A dialética de Adorno denuncia os terrenos baldios da totalidade. O que, do ponto de vista lógico, torna-o um escritor do ininterrupto lamento, mas também do raro alento. Como escreve Terry Eagleton: "O vazio doloroso que uma razão predatória abriu em nossa natureza deve ser mantido aberto, pois só nesse espaço algo mais criativo poderá germinar; e aquilo com que o preencheríamos não passaria de ilusão" ${ }^{20}$. Lidar com este elemento surpreendente em Adorno é o que há de mais difícil para uma crítica filosófica obtusa.

Como o intelectual independente e o filósofo-escritor estão inseridos na constelação da vida danificada, é fundamental entendê-los enquanto análogos a estertores desta vida condicionada ao sofrimento. Aliás, essa é a ideia central da epígrafe de Ferdinand Kürnberger: "A vida não vive".

A vida se transformou em algo meramente suportável e está sendo arrastada por outras forças não naturais. É certo que o motivo filosófico aqui é evidentemente marxiano. No entanto, o relevo das reflexões propostas por Adorno, cujo ponto de partida é a vida danificada, está para além de Marx. Pois ao considerar que também a vida vivida pelos limites críticos (o intelectual independente e o filósofo-escritor) está danificada, Adorno acaba atestando que qualquer expectativa edificante ou glorificante depositada na filosofia marxiana está completamente extraviada de seu tempo e lugar. De modo mais amplo, contradiz e se afasta completamente do paradigma da Antiguidade que visava a

\footnotetext{
${ }^{19}$ Ibidem, p. 7 .

${ }^{20}$ EAGLETON, Terry. A ideologia da estética. Tradução: Mauro Sá Rego Costa. Rio de Janeiro: Jorge Zahar, 1993, p. 262.
} 
realização de uma vida reta e feliz. Essa percepção do extravio e do afastamento se mantém no pensamento de Adorno, pois em Dialética negativa, quase duas décadas depois, ele afirma, de modo geral, que "a filosofia, que um dia pareceu ultrapassada, mantém-se viva porque se perdeu o instante de sua realização." ${ }^{21}$

Para Adorno, é justamente em função de um extravio e seu decorrente reconhecimento, a saber, de não mais poder sonhar com a edificação, com a glória e com a apoteose, que a filosofia tem ainda algum sentido - ou todo o sentido, quando pensado como oportunidade última. $\mathrm{Na}$ análise de Eagleton:

Como seu grande exemplo, Samuel Beckett, Adorno escolhe ser pobre mas honesto; prefere sofrer os limites do espaço teórico constrito em que está aprisionado, que trair um sofrimento humano mais fundamental, ao recalcar essas manobras dolorosas. Os trapos da autenticidade que se podem preservar depois de Auschwitz consistem em manter-se teimosamente segurando os chifres de um dilema impossível, consciente de que o abandono da utopia é tão traiçoeiro quanto a esperança nela; que as negações da realidade são tão indispensáveis quanto ineficazes, e que a arte é ao mesmo tempo preciosa e sem valor. Adorno transforma em virtude a sua vulnerabilidade agoniada, como se isso fosse toda a honestidade que esses dias podem nos dar. ${ }^{22}$

Faz parte do filosofar o ato de atormentar-se com as frustrações próprias da reflexão. Nós, profissionais da filosofia, muitas vezes esquecemos isso; e isso não é mero detalhe. Christoph Türcke atenta para a manutenção da má consciência: "Filosofia que não tem má consciência, não tem consciência adequada de si mesma. Falta-lhe a marca decisiva de qualquer filosofia: a auto-reflexão." ${ }^{23}$ Türcke pontua também a respeito da filosofia: "Só pela vontade de desistir de si mesma ela pode continuar dignamente. Só ao desconfiar de sua tradição, de seus próprios métodos, sua terminologia, suas formas literárias, ela pode tornar-se confiável." ${ }^{24}$

Consciente de seu papel como filósofo, Adorno considera a reflexão sempre como auto-reflexão. Nesse sentido, como ele é consciente de que

\footnotetext{
${ }^{21}$ ADORNO, Theodor W. Dialética negativa. Tradução: Marco Antonio Casanova. Rio de Janeiro: Jorge Zahar, 2009.

${ }^{22}$ EAGLETON, 1993, p. 259.

${ }^{23}$ TÜRCKE, Christoph. "Pronto-socorro para Adorno: fragmentos introdutórios para a dialética negativa". In: ZUIN, A.; PUCCI, B.; RAMOS-DE-OLIVEIRA, N. (Orgs.) Ensaios frankfurtianos. São Paulo: Cortez, 2004, p. 46.

${ }^{24}$ Ibidem, p. 47.
} 
seu escrito filosófico - como produção intelectual que é - agoniza sob a sombra do modelo de produção vigente, insere no próprio escrito o lamento dessa determinação: o fato de saber-se determinado. A vida vivida deixa escapar a verdade a respeito da dignidade, que será realizável em um contexto que compromete a própria dignidade. Essa verdade, como toda a verdade, sempre existiu, pois a moral sempre se colocou como desafio frente a contradições expostas na vida vivida. Afinal, para Adorno, é a história que está contida na verdade, e não o seu contrário:

\begin{abstract}
A única esperança autêntica é a que se prende ao conhecimento de que as coisas vêm sendo terríveis há muito tempo, e esta é uma esperança que, ao mesmo tempo, arrisca perder esse conhecimento e cair novamente na inautenticidade. Só mantendo-nos fiéis ao passado podemos nos livrar de suas garras terrificantes, mas esta fidelidade sempre ameaça paralisarnos. O problema é o de como aliviar e manter-se fiel ao sofrimento, ao mesmo tempo, já que uma alternativa está sempre a ponto de suprimir a outra. Adorno é como um cirurgião ferido, simultaneamente médico e paciente; e suas feridas, como Wittgenstein diria, foram o resultado de tentar mergulhar de cabeça contra os limites da linguagem. A única cura para nossa doença é que ela piore - que as feridas infligidas à humanidade por sua própria loucura sejam deixadas inflamar, sem atendimento, pois sem seu testemunho mudo, esqueceremos que um remédio é mesmo necessário e nos retrairemos na inocência. ${ }^{25}$
\end{abstract}

A estranheza que Adorno sente diante do sistema se manifesta como forma para expressar sua produção intelectual. Assim, não haveria, para Adorno e seu instante, outra filosofia que não fosse composta de estilhaços:

Apesar disso, é no olhar para o desviante, no ódio à banalidade, na busca do que ainda não está gasto, do que ainda não foi capturado pelo esquema conceitual geral, que reside a derradeira chance do pensamento. Em uma hierarquia intelectual que incessantemente exige de todos prestação de contas, só a irresponsabilidade é capaz de chamar imediatamente tal hierarquia por seu nome. A esfera da circulação, cujas marcas são ostentadas pelos outsiders intelectuais, oferece ao espírito de que se faz comércio os últimos refúgios, no momento mesmo em que estes a rigor já não existem mais. ${ }^{26}$

\footnotetext{
${ }^{25}$ EAGLETON, 1993, p. 262.

${ }^{26}$ ADORNO, 1993, p. 58.
} 
Adorno torna possível a percepção de que o fragmento não é simplesmente um caco qualquer do sistema. Fragmentos podem ser fagulhas e migalhas de uma imposição, porém isso não significa que devam ser desprezados. O fragmento refletido confronta o todo, subverte a norma vigente. Porém, de modo peculiarmente novo, Adorno inclui como função da crítica entender os perigos da subversão. Com isso, ele não apenas repudia a possibilidade de uma filosofia profissional qualquer, mas, sobretudo, causa mal-estar à classe dos críticos profissionais do sistema.

É por isso que os acadêmicos sempre desconfiarão de Adorno, pois costumam produzir filosofia sem notar que essa produção está submetida a forças materiais que, ao danificarem a vida, consequentemente danificam a produção intelectual derivada da vida. Ou seja, também a vida acadêmica não vive e apenas agoniza perante as exigências que lhes são impostas como hipóstase do processo de produção material. A agonia é sua constância existencial; jamais o viver autônomo.

No fim das contas, o profissional da filosofia não escapa de ser também um trabalhador. E sendo trabalhador é mercadoria. Como expressa Julian Roberts:

Na moderna economia de mercado, as mercadorias não são meramente
itens físicos, mas seres humanos, ou, mais precisamente, segmentos de
vida humana. Os trabalhadores possuem uma constante tendência a se
tornarem mercadorias, uma vez que suas qualidades (suas
"qualificações”) e todas as características que os tornam interessantes ao
capitalista que os adquire (especialmente sua juventude e aptidão) podem
ser determinadas de acordo com as normas gerais. O capitalismo necessita
de mercadorias humanas previsíveis, indivíduos cuja individualidade se
torne subordinada ao conjunto de habilidades específicas para as diversas
áreas da produção. ${ }^{27}$

Encontrar prazer no trabalho é porta de entrada para a expiação, pois a divisão do trabalho configura o modelo vigente de organização, o qual apenas permite o prazer surgido fora de seus domínios. Mas por ser um modelo opressor, o "fora" é só uma sombra sua. Nesse sentido, em uma perspectiva adorniana, a mobilização da curiosidade e de outros elementos criativos - que se deslocam da necessidade de se tornarem

\footnotetext{
${ }^{27}$ ROBERTS, Julian. “A dialética do esclarecimento”. In: RUSH, Fred. (Org.) Teoria Crítica. $2^{\text {a }}$ Ed. Tradução: Beatriz Katinsky e Regina Andrés Rebollo. São Paulo: Ideias \& Letras, 2008, p. 91.
} 
moeda de barganha - é um fôlego de resistência paradoxal, pois corre o risco iminente de tornar-se bandeira política e, nesse caso, não terá a oportunidade de usar sua ingenuidade como álibi. Adorno assume a difícil e quase incompreensível tarefa de preservar esse fôlego de resistência de qualquer uso, pois é pensado por ele como fim em si mesmo. Esta tarefa é da mesma ordem argumentativa de que a obra de arte não pode ser instrumento político. Somente uma espécie de suspensão voluntária das engrenagens do mundo moderno seria um testemunho compatível com sua autonomia. Com isso, no pensamento adorniano está implícita a convicção de que todos os discursos políticos, por mais libertadores que possam se apresentar, já estão contidos na engrenagem que os reifica. Os partidos políticos, sempre evitados por Adorno, sofrem congenitamente do mesmo mal que criticam, culminando, no caso dos revolucionários, na absurda pretensão de tomar posse da solidariedade.

Como a filosofia se vê comprometida com algo que não é ela, o discurso da autonomia necessita revisão. Em contrapartida, a providência adorniana de partir do interesse pelo particular - sem almejar uma intocável universalidade - permaneceu alvo de acusações de falta de consistência. Em favor de sua filosofia, escreve Adorno:

O conhecimento só é capaz de proporcionar um alargamento se ele adere ao indivíduo com uma tal insistência que seu isolamento se desfaz. Decerto, isso pressupõe também uma relação com o universal, mas não de subsunção, porém uma que seja quase o contrário desta. A mediação dialética não é o recurso a algo mais abstrato, e sim o processo de dissolução do concreto no interior de si mesmo. [...] A moralidade do pensamento consiste em não proceder de maneira teimosa nem soberana, nem cega nem vazia, nem atomística nem coerente. ${ }^{28}$

Assim, Adorno empenha sua sensibilidade na tarefa de buscar vestígios de dissolução nos mais imprevistos e inesperados eventos do cotidiano. Qualquer truculência ou desleixo humano, por si só, imprime uma particular refutação ao sistema. A rudeza na hora de abrir ou fechar

${ }^{28}$ ADORNO, 1993, p. 64. 
uma porta ${ }^{29}$, o zelo pela automação eletrônica e a própria rapidez barulhenta das ruas demonstram uma dependência do indivíduo em relação a alguma forma preestabelecida de estrutura. Essa influência pode ser verificada no seguinte trecho:

O poder magnético que as ideologias exercem sobre os homens, mesmo quando já dão sinais de estarem rotas, explica-se, para além da psicologia, pela decadência objetivamente determinada da evidência lógica enquanto tal. As coisas chegaram ao ponto em que a mentira soa como verdade e a verdade como mentira. Cada declaração, cada notícia, cada pensamento está preformado pelos centros da indústria cultural. O que não traz a marca familiar dessa preformação está, de antemão, destituído de credibilidade, tanto mais que as instituições de opinião pública fazem acompanhar aquilo que divulgam de milhares de comprovações factuais e de toda plausibilidade, de que pode se apoderar o poder de disposição total. A verdade que tenta se opor a isso não só porta o caráter de inverossímil como é, além disso, pobre demais para entrar em concorrência com o aparato de divulgação altamente concentrado. ${ }^{30}$

Essa estrutura raramente deixa de ser previamente consentida pelo indivíduo na contemporaneidade. Consistiria aí, na possibilidade de enxergar sua própria alienação, alguma esperança - sempre volátil - para o indivíduo adorniano. "Só a estranheza é o antídoto para a alienação"31, diz Adorno. Indelevelmente massacrado, o indivíduo segue vivendo e nutrindo-se de uma circunstância fragilizada, pauperizada, no sentido benjaminiano de experiência:

No deperecimento da experiência, um fato possui uma considerável responsabilidade: que as coisas, sob a lei de sua pura funcionalidade, adquirem uma forma que restringe o trato delas a um puro manejo, sem tolerar um só excedente - seja em termos de

\footnotetext{
${ }^{29}$ Cf. EAGLETON, 1993, p. 26o e ADORNO, 1993, p. 33.

${ }^{30}$ ADORNO, 1993, p. 94.

${ }^{31}$ Ibidem, p. 81.
} 
liberdade de comportamento, seja de independência da coisa - que subsista como núcleo da experiência porque não é consumido pelo instante da ação. ${ }^{32}$

Assim é o choque contra o ideal da indústria cultural: no mínimo, injusto, isto é, um embate de forças desproporcionais. Muitas vezes, aquele que sente a estranheza chega a ser considerado incrédulo. $\mathrm{O}$ viço da vida está comprometido por uma percepção estética que não é livre, por exigência da estrutura de realidade que submete o ser humano à condição de decorrência. Consequentemente, a obviedade da vida que é oferecida ao sujeito contemporâneo é capaz de enclausurá-lo entre o que o determina e o que pode fazê-lo vir a ser. Adorno é sutil na observação do mascaramento sobre essa estrutura de realidade, quando observa que "disfarçada de força, a fraqueza entregou à ideologia o pensamento da burguesia supostamente ascendente, já na época em que esta trovejava contra a tirania". 33

\section{Considerações finais}

O elemento nocivo da racionalidade situa-se de forma paralela à condição natural do mundo. O homem, como ser racional, é uma imperiosa ameaça à Natureza, incluindo seu semelhante. "A dissolução das racionalizações torna-se ela mesma uma racionalização". ${ }^{34}$ Contudo, a elaboração tradicional da metafísica parece insuficiente para explicar um possível desvio ou descarrilamento de propósitos na racionalidade humana. E o pensamento de Adorno, que não pretende ser suficiente como solução, é uma tentativa de fazer nossa racionalidade olhar para seus próprios equívocos. Por fim, todo ele é um movimento que reforça a antiga noção de que a produção intelectual humana é seu exercício mais dignificante e não pode ser vivenciado sob a instrumentalização que forças pré-determinadas - que não são mais uma questão metafísica de limites da razão - venham lhe impor.

\footnotetext{
${ }^{32}$ Ibidem, p. 33.

${ }^{33}$ Ibidem, p. 76-77.

${ }^{34}$ Ibidem, p. 56.
} 
M. dos Santos - Adorno e os estertores da derradeira chance do pensamento 743

O paradoxo maior consiste na suspeita de que a derradeira chance do pensamento, resguardando sua autonomia, precisa antes se emancipar das instituições nas quais originalmente ele deveria florescer.

\section{Referências}

ADORNO, Theodor W. Minima moralia: reflexões a partir da vida danificada. Tradução: Luiz Eduardo Bicca. $2^{\text {a }}$ Ed. São Paulo: Ática, 1993.

Dialética negativa. Tradução: Marco Antonio Casanova. Rio de Janeiro: Jorge Zahar, 2009.

EAGLETON, Terry. A ideologia da estética. Tradução: Mauro Sá Rego Costa. Rio de Janeiro: Jorge Zahar, 1993 .

HORKHEIMER, Max; ADORNO, Theodor. Dialética do esclarecimento. Tradução de Guido de Almeida. Rio de Janeiro: Jorge Zahar, 1985.

ROBERTS, Julian. "A dialética do esclarecimento". In: RUSH, Fred. (Org.) Teoria Crítica. $2^{\mathrm{a}}$ Ed. Tradução: Beatriz Katinsky e Regina Andrés Rebollo. São Paulo: Ideias \& Letras, 2008, p. 85-103.

TÜRCKE, Christoph. "Pronto-socorro para Adorno: fragmentos introdutórios para a dialética negativa”. In: ZUIN, A.; PUCCI, B.; RAMOS-DE-OLIVEIRA, N. (Orgs.) Ensaios frankfurtianos. São Paulo: Cortez, 2004, p. 41-59.

\section{Endereço postal}

CCHS - Centro de Ciências Humanas e Sociais

Universidade do Vale do Taquari - Univates

Av. Avelino Talini, 171 Sala 202/2

Lajeado - RS, Brasil

Data de recebimento:25/05/2018

Data de aceite:17/09/2018 